\title{
Oral Anaerobic Microflora and Pregnancy Complication
}

\author{
Irena Andonova*(i), Vasil Iliev(i) \\ Department of Gynecology and Obstetrics, Zan Mitrev Clinic, Skopje, Republic of Macedonia
}

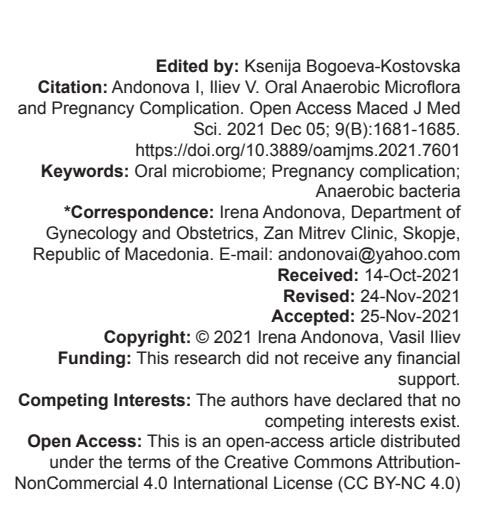

Introduction

Pregnancy induces many physiological changes in expectant mother, and one of them is a shift in the microbial composition of the body. The oral cavity is a complex and diverse microbiome of over 700 inhabitants identified in the human oral microbiome database [1]. Balanced microbial flora helps maintain a stable oral and general health, hereby, the alteration in the oral microbial community with predominantly anaerobic species during pregnancy can affect maternal health and birth outcomes [2], [3].

Oral anaerobic bacteria can affect the fetoplacental unit directly through bloodstream or indirectly through systemic inflammatory mediators, leading to adverse pregnancy outcomes [4], [5], [6]. Researchers have reported higher level of $P$. gingivalis in the oral cavity among women with preterm deliveries [7], [8]. In addition,the higher risk for SGA neonates has also been reported in pregnant women with periodontal anaerobes present in their subgingival plaque [9]. However, in contrast, Costa et al. did not confirm these findings [10].

The etiology of poor obstetric outcomes is multifactorial, with many idiopathic causes. In the literature, infection and inflammation are often responsible for the complications of pregnancy, according to some studies up to $60 \%$ and the evidence for this claim in perinatology came from pathologists, by analyzing the placenta of children born with poor pregnancy outcomes [11], [12]. Accurate diagnosis of the source of infection, as well as a clear understanding of the association between anaerobic microorganisms and adverse birth outcomes are crucial to patient management. Therefore, the aim of the study is to focus on the implications of oral anaerobic microorganisms on adverse birth outcomes.

\section{Materials and Methods}

The case-control study enrolled 110 pregnant women who signed information consent.

The study population included-Group I: 40 pregnant women with signs of preterm labor. Group II: 20 pregnant women diagnosed with IUGR, based on fetal ultrasound biometrics. Group III: 50 pregnant women who gave birth to neonate with normal birth weight at term. 
Exclusion criteria: The exclusion criteria include multiple gestations, congenital uterine anomaly, history of second trimester abortion or preterm delivery, cerclage in the present pregnancy, substance abuse, and smoking.

Methods: Preterm labor was diagnosed on clinical criteria of four uterine contractions every $20 \mathrm{~min}$ or eight every $60 \mathrm{~min}$, accompanied by cervical shortening of at least $80 \%$ or cervical dilatation greater than $2 \mathrm{~cm}$, before 37 week of gestation.

Fetal biometry was determined using fetal parameters BPD, $\mathrm{HC}, \mathrm{AC}$, and $\mathrm{FL}$, on the basis of which the obstetric software gave the fetal weight and the gestational week to which the fetal biometric tests corresponded [13]. The fetal weight values obtained were compared on population curves to determine if there was a deviation of $<10 \%$ for the gestational week, which was the diagnostic criterion for selecting IUGR fetuses.

Obstetric and ultrasound examination, microbiological subgingival swab was taken up to $24 \mathrm{~h}$ after the hospitalization of the case-group patients. The microbiological sublingual swab in the control group patients was taken up to $48 \mathrm{~h}$ after delivery. Samples were collected with complete aseptic precautions, swabs were transported in an anaerobic transport medium, and they were cultured on Schaedler agar for $48 \mathrm{~h}$. Colonies were analyzed with Vitek 2 ANC ID card and Vitek NH ID card panels, according to the methods that were suggested bymanufacturer [14].

The data were analyzed with the SPSS computer program (version 17). In the analysis of the attribute data series, percentages of the structure (\%) were determined, and the differences between the three groups were tested using the Pearson Chi-square test, and the Fisher Exact test/Monte Carlo Sig. In the series with numerical data, descriptive statistics were developed and the distribution of data was tested using the Kolmogorov-Smirnov test, the Lilliefors test, and the Shapiro-Wilks test ( $p)$. In assessing the predictive values of certain parameters for preterm delivery and birth of babies small for gestational age, logistic regression analysis (Wald, Exp (B), 95.0\% Cl for Exp (B), p).was used.

\section{Results}

There was no statistical significance in the distribution of patient age between groups. There was no significant difference between the groups in obstetrical risk variables for adverse pregnancy outcomes shown in this study. The patients in our study were relatively homogeneous based on socio-economic and demographic factors, level of education, employment, and monthly income. There are studies in the literature that have shown that preterm birth occurs more often in the lower socio-economic class; however, this factor has no significant effect on the outcome of this study, due to lack of significant difference between the groups.

The data presented in Table 1 refer to the findings of oral anaerobic bacteria in the three groups of patients. For Fisher's Exact test $=39.64$ and $p<0.01$ ( $p=0.001$ )/Monte Carlo sig./0.000-0.002/between the three groups of pregnant women, there is a significant difference in the findings of oral anaerobic bacteria.

Table 1: Isolated oral anaerobic bacteria between groups

\begin{tabular}{|c|c|c|c|c|}
\hline \multirow[t]{2}{*}{ Isolated oral anaerobic bacteria } & \multicolumn{3}{|l|}{ Groups } & \multirow[t]{2}{*}{ Total } \\
\hline & I & II & III & \\
\hline \multicolumn{5}{|l|}{ Negative } \\
\hline Count & 12 & 6 & 33 & 51 \\
\hline$\%$ & $30.0 \%$ & $30.0 \%$ & $66.0 \%$ & $46.4 \%$ \\
\hline \multicolumn{5}{|l|}{ Porphyrmonas gingivalis } \\
\hline Count & 6 & 4 & 1 & 11 \\
\hline$\%$ & $15.0 \%$ & $20.0 \%$ & $2.0 \%$ & $10.0 \%$ \\
\hline \multicolumn{5}{|l|}{ Veilonella parvulla } \\
\hline Count & 4 & 1 & 3 & 8 \\
\hline$\%$ & $10.0 \%$ & $5.0 \%$ & $6.0 \%$ & $7.3 \%$ \\
\hline \multicolumn{5}{|l|}{ Fusobacterium lentum } \\
\hline Count & 4 & 1 & 3 & 8 \\
\hline$\%$ & $10.0 \%$ & $5.0 \%$ & $6.0 \%$ & $7.3 \%$ \\
\hline \multicolumn{5}{|l|}{ Actynomyces odontolyticus } \\
\hline Count & 3 & 1 & 3 & 7 \\
\hline$\%$ & $7.5 \%$ & $5.0 \%$ & $6.0 \%$ & $6.4 \%$ \\
\hline \multicolumn{5}{|l|}{ Eikenella corrodens } \\
\hline Count & 4 & 2 & 0 & 6 \\
\hline$\%$ & $10.0 \%$ & $10.0 \%$ & $0.0 \%$ & $5,5 \%$ \\
\hline \multicolumn{5}{|l|}{ Peptostreptococcus micros } \\
\hline Count & 2 & 0 & 3 & 5 \\
\hline$\%$ & $5.0 \%$ & $0.0 \%$ & $6.0 \%$ & $4.5 \%$ \\
\hline \multicolumn{5}{|l|}{ Prevotella intermedia } \\
\hline Count & 3 & 1 & 0 & 4 \\
\hline$\%$ & $7.5 \%$ & $5.0 \%$ & $0.0 \%$ & $3.6 \%$ \\
\hline \multicolumn{5}{|l|}{ Eubacterium lentum } \\
\hline Count & 0 & 0 & 3 & 3 \\
\hline$\%$ & $0.0 \%$ & $0.0 \%$ & $6.0 \%$ & $2.7 \%$ \\
\hline \multicolumn{5}{|l|}{ Tannerella forsythia } \\
\hline Count & 1 & 2 & 0 & 3 \\
\hline$\%$ & $2.5 \%$ & $10.0 \%$ & $0.0 \%$ & $2.7 \%$ \\
\hline \multicolumn{5}{|l|}{ Streptococcus intermedius } \\
\hline Count & 0 & 1 & 1 & 2 \\
\hline$\%$ & $0.0 \%$ & $5.0 \%$ & $2.0 \%$ & $1.8 \%$ \\
\hline \multicolumn{5}{|l|}{ Actynomyces Israeli } \\
\hline Count & 1 & 0 & 0 & 1 \\
\hline$\%$ & $2.5 \%$ & $0.0 \%$ & $0.0 \%$ & $0.9 \%$ \\
\hline \multicolumn{5}{|l|}{ Bifidobacterium spc } \\
\hline Count & 0 & 1 & 0 & 1 \\
\hline$\%$ & $0.0 \%$ & $5.0 \%$ & $0.0 \%$ & $0.9 \%$ \\
\hline
\end{tabular}

The enter method was used to determine the predictive values of isolated oral bacteria for preterm birth. The global accuracy of this model to predict preterm birth is $71.70 \%$. The sensitivity is $56.50 \%$ and the specificity is $81.10 \%$. Negative oral swabs were taken as a reference category.

As demonstrated by the tables, Porphyrmonas gingivalis (Wald $=5.56 / p<0.05(p=0.02)$ ), followed by Prevotella intermedia (Wald $=3.73 / p>0.05(p=0.053)$ ) had the greatest impact on preterm birth. Pregnant women who were found to have Porphyrmonas gingivalis were 6.65 times more likely to have a preterm birth than pregnant women with negative oral swabs, (95.0\% Cl: 1, 38-32.11/p < 0.05) (Table 2).

The ROC area is 0.734 (Figure).

In determining the predictive values of oral swabs for the birth of babies small for gestational age, the enter method was used. The global accuracy of this model to suggest the birth of babies small for gestational age is $68.30 \%$. 
Table 2: The predictive values of oral anaerobes for preterm birth

\begin{tabular}{|c|c|c|c|c|c|c|c|c|}
\hline \multirow[t]{2}{*}{ Oral swabs } & \multirow[t]{2}{*}{ B } & \multirow[t]{2}{*}{ SE } & \multirow[t]{2}{*}{ Wald } & \multirow[t]{2}{*}{ df } & \multirow[t]{2}{*}{ Sig. } & \multirow[t]{2}{*}{$\operatorname{Exp}(\mathrm{B})$} & \multicolumn{2}{|c|}{$\begin{array}{l}95,0 \% \mathrm{Cl} \text { for } \\
\operatorname{Exp}(\mathrm{B})\end{array}$} \\
\hline & & & & & & & Lower & Upper \\
\hline Peptostreptococcus micros (1) & 1.34 & 1.50 & 0.79 & 1 & 0.37 & 3.80 & 0.20 & 72.00 \\
\hline Veilonella parvulla (1) & 0.93 & 1.04 & 0.80 & 1 & 0.37 & 2.53 & 0.33 & 19.53 \\
\hline Fusobacterium nucleatum (1) & 0.93 & 1.04 & 0.80 & 1 & 0.37 & 2.53 & 0.33 & 19.53 \\
\hline Porphyrmonas gingivalis (1) & 1.90 & 0.80 & 5.56 & 1 & 0.02 & 6.65 & 1.38 & 32.11 \\
\hline Eikenella corrodens (1) & -0.27 & 1.21 & 0.05 & 1 & 0.82 & 0.76 & 0.07 & 8.07 \\
\hline Tannerella forsythia (1) & 2.03 & 1.32 & 2.35 & 1 & 0.13 & 7.60 & 0.57 & 101.79 \\
\hline Prevotella intermedia (1) & 2.43 & 1.26 & 3.73 & 1 & 0.053 & 11.40 & 0.97 & 134.55 \\
\hline Constant & -1.34 & 0.50 & 7.05 & 1 & 0.01 & 0.263 & & \\
\hline
\end{tabular}

Tannerella forsythia (Wald $=1.24 / \mathrm{p}>0.05$ ) $(\mathrm{p}=0.27$ ) and Porphyrmonas gingivalis (Wald = $0.58 / p>0.05$ ) had the greatest influence on the birth of babies small for gestational age. Pregnant women who have been diagnosed with Tannerella forsythia were 4.29 times more likely to give birth to babies small for gestational age compared to pregnant women with negative oral swabs; however, the effect is negligible (95.0\% Cl: 0.33-55.59/p > 0.05).

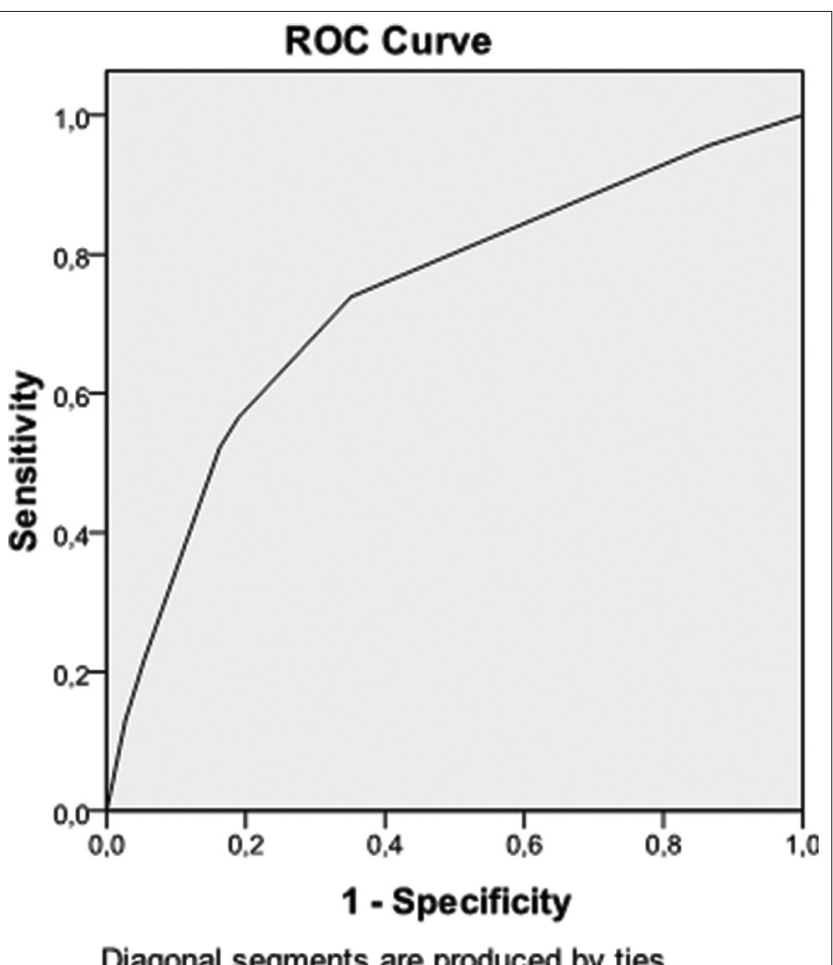

Figure 1: The predictive values of oral anaerobes for preterm birth

Pregnant women who were found to have Porphyrmonas gingivalis were 1.79 times more likely to give birth to babies small for their gestational age compared to pregnant women with negative oral swabs, the effect is significant $(95.0 \%$ Cl: 0.40-7.91/p < 0.05) (Table 3).

Table 3: Predictive values of oral swabs for the birth of babies small for gestational age

\begin{tabular}{|c|c|c|c|c|c|c|c|c|}
\hline \multirow[t]{2}{*}{ Oral swabs } & \multirow[t]{2}{*}{ B } & \multirow[t]{2}{*}{ SE } & \multirow[t]{2}{*}{ Wald } & \multirow[t]{2}{*}{ df } & \multirow[t]{2}{*}{ Sig. } & \multirow[t]{2}{*}{$\operatorname{Exp}(\mathrm{B})$} & \multicolumn{2}{|c|}{$\begin{array}{l}95.0 \% \text { Cl for } \\
\operatorname{Exp~(B)~}\end{array}$} \\
\hline & & & & & & & Lower & Upper \\
\hline Actynomyces odontolyticus (1) & -0.34 & 1.24 & 0.07 & 1 & 0.79 & 0.71 & 0.06 & 8.15 \\
\hline Veilonella parvulla (1) & -0.62 & 1.21 & 0.27 & 1 & 0.61 & 0.54 & 0.05 & 5.72 \\
\hline Fusobacterium nucleatum (1) & -0.62 & 1.21 & 0.27 & 1 & 0.61 & 0.55 & 0.05 & 5.72 \\
\hline Porphyrmonas gingivalis (1) & 0.58 & 0.76 & 0.58 & 1 & 0.45 & 1.79 & 0.40 & 7.91 \\
\hline Eikenella corrodens (1) & 0.07 & 0.98 & 0.01 & 1 & 0.94 & 1.07 & 0.16 & 7.31 \\
\hline Tannerella forsythia (1) & 1.46 & 1.31 & 1.24 & 1 & 0.27 & 4.29 & 0.33 & 55.59 \\
\hline Prevotella intermedia (1) & -0.34 & 1.24 & 0.07 & 1 & 0.79 & 0.71 & 0.06 & 8.15 \\
\hline Constant & -0.76 & 0.46 & 2.77 & 1 & 0.10 & 0.47 & & \\
\hline
\end{tabular}

The ROC area is 0.627 (Figure 2).

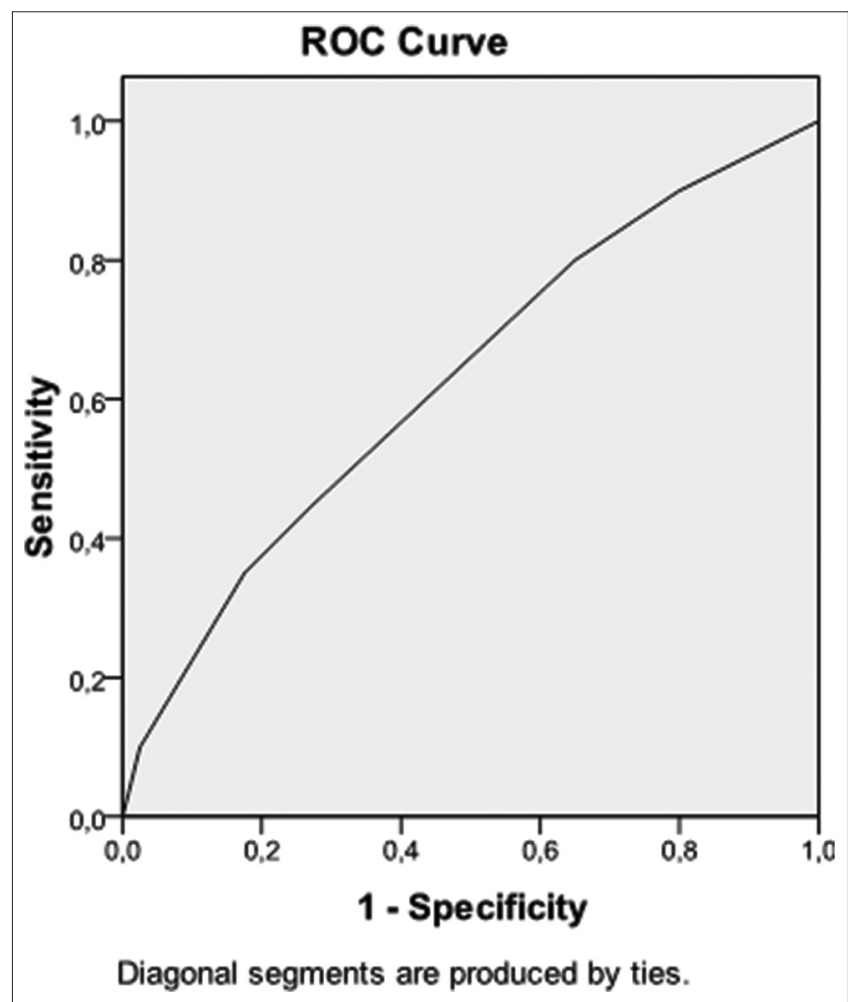

Figure 2: The predictive values of oral anaerobes for SGA baby

Discussion

Poor obstetric outcomes are a major medical and social problem, the incidence of which has remained the same in recent years, despite overall advances in medicine. In the past decade, there has been progress in elucidating the etiology and pathogenesis of adverse pregnancy outcomes, by recognizing new etiological factors and various mechanisms involved in pregnancy complications.

So far, all attention has been focused on the ascending path of infection such as bacterial vaginosis. However, in recent years, it has been hypothesized that infection from distant sites of the fetoplacental unit may also play a part in pregnancy complication. The pathologists have shown a hematogenous route of infection of the fetoplacental unit, which is characterized by villitis and interviliositis without an infection present in the chorion, leading to the conclusion that bacteria reached the uterus through the bloodstream. As a distant place of infection, this study examined the subgingival sulcus, as a reservoir of Gram-negative anaerobes.

In 2017, a study showed that the FcyRIlb gene polymorphism in women was associated with adverse pregnancy outcomes, as well as low IgG antibody production for oral anaerobic bacteria caused by F $\gamma \gamma$ II 
gene polymorphism can lead to preterm delivery. IgG is the only globulin that crosses the placenta, protecting the fetus in utero. Low IgG antibody production against Porphyromonas gingivalis in early pregnancy has been associated with IUGR and preterm birth under 28 GW [15], [16].

This study supports the hypothesis that the presence of oral anaerobic bacteria in pregnant women increases the risk of developing complication in pregnancy. The levels of anaerobic oral bacteria tended to be higher in the case groups compared to the term deliveries. The percentage of negative swabs is $66 \%$ in the control group and $30 \%$ in the case groups. The bacteria Prevotella intermedia and Eikenella corrodens were isolated only in the case groups, while Eubacterium lentum was isolated from subgingival swabs only in the control group.

However, little is yet known about changes in the subgingival microflora in pregnant women and its impact on poor obstetric outcomes. Various studies from different parts of the world have shown an isolation rate of $52-100 \%$ for strict anaerobes in women with preterm delivery and $28-70 \%$ in healthy subjects. Variation in the type of isolated anaerobes from the sublingual sulcus may also depend on geographical location and geographical differences. The mere presence of an anaerobic or pathogen may not be sufficient to cause disease on its own but in combination with genetic and environmental factors can lead to the development of pregnancy complication.

In our study, pregnant women who tested positive for Porphyrmonas gingivalis were 6 times more likely to have a preterm birth and 2 times more likely to have IUGR fetus than pregnant women with negative oral swabs, and the impact was statistically significant. Similar positive associations were reported by different authors [7], [17], and [18], whose studies detected $P$. Gingivalis, in placental tissue of mother with adverse pregnancy outcomes. Another study showed that $P$. gingivalis DNA in human chorionic villous tissue or amniotic fluid has been linked to preterm labor and IUGR. Presence of $P$. gingivalis in the placenta or umbilical cord has been associated with preterm birth [19]. There are multiple mechanisms described by which $P$. gingivalis could be related to the above. In the murine model, changes in placental tissues have been observed after translocation of $P$. gingivalis, including necrosis and increased inflammation. They also detected another oral pathogen F. nukleatum in the chorionic tissue of pregnant women with highrisk pregnancies, which in our study did not show a significant impact.

Experimental study on mice with induced oral $P$. gingivalis infection was found to significantly increased premature birth and IUGR in mice, compared to the controls $(p<0.01)$ [20]. Likewise, several studies have demonstrated a significant increase of periodontal pathogen levels in subgingival sulcus in mothers with preterm birth. Moreover, when oral anaerobic bacteria were not detected in the mothers' periodontal pockets, newborns were $129 \%$ more likely to have a normal birth weight. The presence of Eikenella corrodens $p=0.022$ was associated with preterm birth, and the presence of Porphyromonas gingivalis $p=0.008$ was associated with IUGR [21], [22].

\section{Conclusion}

Based on the results of this study, oral bacteria can play an unrecognizable role in the development of intrauterine infections, which can lead to pregnancy complications [23]. It is logical to assume that infection of oral periodontal tissues with Gram-negative anaerobic bacteria is a reservoir of microbial products that elicit a host immune response.

There is also ample evidence to support the theory of hematogenous translocation of periodontal pathogens to the fetoplacental unit associated with the cumulative inflammatory response. This inflammatory process may be the last link in the oral-fetal cascade that results in a negative pregnancy outcome.

The question of finding an effective therapy and strategy to improve pregnancy outcomes is rooted in our understanding of the mechanisms that cause preterm births and complications of pregnancy. Only when we are fully aware of the mechanism of action, we will be able to conduct and design intervention studies targeting the appropriate population, using the appropriate therapeutic approach and measuring the relevant measures for poor obstetric outcomes. It remains important to recognize the need to improve oral health during pregnancy, to maintain good general health and provide the necessary mechanism for its promotion.

\section{References}

1. Chen $\mathrm{T}, \mathrm{Yu}$ WH, Izard J, Baranova OV, Lakshmanan A Dewhirst FE. The Human Oral Microbiome Database: A web accessible resource for investigating oral microbe taxonomic and genomic information. Database (Oxford). 2010;2010:baq013. https://doi.org/10.1093/database/baq013 PMid:20624719

2. Nuriel-Ohayon $\mathrm{M}$, Neuman $\mathrm{H}$, Koren O. Microbial changes during pregnancy, birth, and infancy. Front Microbiol. 2016;7:1031. https://doi.org/10.3389/fmicb.2016.01031 PMid:27471494

3. Mesa MD, Loureiro B, Iglesia I, Gonzalez SF, Olivé EL, Algar OG, et al. The evolving microbiome from pregnancy to early infancy: A comprehensive review. Nutrients. 2020;12(1):133. https://doi. org/10.3390/nu12010133 
PMid:31906588

4. Pretorius $\mathrm{C}$, Jagatt A, Lamont RF. The relationship between periodontal disease, bacterial vaginosis, and preterm birth. J Perinat Med. 2007;35(2):93-9. https://doi.org/10.1515/ JPM.2007.039

PMid:17343541

5. Ye C, Xia Z, Tang J, Khemwong T, Kapila Y, Kuraji R, et al. Unculturable and culturable periodontal-related bacteria are associated with periodontal inflammation during pregnancy and with preterm low birth weight delivery. Sci Rep. 2020;10:15807. https://doi.org/10.1038/s41598-020-72807-9

6. Madianos PN, Lieff S, Murtha AP, Boggess KA, Auten RL, Beck JD. Maternal periodontitis and prematurity. Part II: maternal infection and fetal exposure. Ann Periodontol. 2013;6(1):17582. https://doi.org/10.1902/annals.2001.6.1.175 PMid:11887461

7. Ye C, Kobayashi H, Katagiri S, Miyasaka N, Takeuchi Y, Kuraji R, et al. The relationship between the anti-Porphyromonas gingivalis immunoglobulin $\mathrm{G}$ subclass antibody and small for gestational age delivery: A longitudinal study in pregnant Japanese women. Int Dent J 2020;70:296-302. https://doi. org/10.1111/idj.12548

PMid:32185796

8. Gomez LA, De Avila J, Castillo DM, Montenegro DA, Trujillo TG Suárez LJ, et al. Porphyromonas gingivalis placental atopobiosis and inflammatory responses in women with adverse pregnancy outcomes. Front Microbiol. 2020;11:591626. https:// doi.org/10.3389/fmicb.2020.591626

PMid:33343532

9. Marakoglu I, Gursoy UK, Marakoglu K, Cakmak H, Ataoglu T. Periodontitis as a risk factor for preterm low birth weight. Yonsei Med J. 2008;49(2):200-3. https://doi.org/10.3349/ ymj.2008.49.2.200

PMid:18452254

10. Costa EM, de Araujo Figueiredo CS, Martins 3RF Ribeiro CC, Alves CM, Sesso ML, et al. Periodontopathogenic microbiota, infectious mechanisms and preterm birth: Analysis with structural equations (cohort-BRISA). Arch Gynecol Obstet 2019;300:1521-30.

11. Ye C, Katagiri S, Miyasaka N, Kobayashi H, Khemwong T, Nagasawa $\mathrm{T}$, et al. The periodontopathic bacteria in placenta, saliva and subgingival plaque of threatened preterm labor and preterm low birth weight cases: A longitudinal study in Japanese pregnant women. Clin Oral Investig. 2020;24(12):4261-70. https://doi.org/10.1007/s00784-020-03287-4 PMid:32333174

12. Tanneeru S, Mahendra J, Shaik MV. Evaluation of microflora (viral and bacterial) in subgingival and placental samples of pregnant women with preeclampsia with and without periodontal disease: A cross-sectional study. J Int Soc Prev Community Dent. 2020;10(2)171-6. https://doi.org/10.4103/ jispcd.JISPCD_341_19 PMid:32670905

13. Hadlock FP. Evaluation of fetal weight estimation procedures.
In: Deter RL, editor. Quantitative Obstetrical Ultrasonography. New York: Wiley Medical; 1981.

14. Mory F, Alauzet C, Matuszeswski C, Riegel P, Lozniewski A Evaluation of the new Vitek 2 ANC card for the identification of medically relevant anaerobic bacteria. J Clin Microbiol. 2009;47(6):1923-6. https://doi.org/10.1128/JCM.01778-08 PMid:19386846

15. Iwanaga $R$, Sugita $N$, Hirano E, Sasahara J, Kikuchi A Tanaka K, et al. FcyRIIB polymorphisms, periodontitis and preterm birth in Japanese pregnant women. J Periodontal Res. 2011;46(3):292-302.

16. Wang Y, Sugita N, Wang I, Meng P, Gao L, Lin J, et al. Relationship between FcyRIIB gene polymorphisms, periodontitis and adverse pregnancy outcomes in pregnant women. Int J Clin Exp Pathol. 2017;10(4):4739-47.

17. Daalderop L, Wieland BV, Tomsin K, Reyes L, Kramer BW, Vanterpool SF, et al. Periodontal disease and pregnancy outcomes: Overview of systematic reviews. JDR Clin TransI Res. 2018;3(1):10-27. https://doi.org/10.1177/2380084417731097 PMid:30370334

18. Hasegawa-Nakamura $K$, Tateishi F, Nakamura $T$, Nakajima $Y$, Kawamata K, Douchi $\mathrm{T}$, et al. The possible mechanism of preterm birth associated with periodontopathic Porphyromonas gingivalis. J Periodontal Res. 2011;46(4):497-504. https://doi. org/10.1111/j.1600-0765.2011.01366.x PMid:21488875

19. Vanterpool SF, Been JV, Houben ML, Nikkels PG, De Krijger RR, Zimmermann LJ, et al. Porphyromonas gingivalis within placental villous mesenchyme and umbilical cord stroma is associated with adverse pregnancy outcome. PLoS One. 2016;11(1):e146157. https://doi.org/10.1371/journal. pone.0146157 PMid:26731111

20. Ao $M$, Miyauchi $M$, Furusho $H$, Inubushi $T$, Kitagawa $M$, Nagasaki A, et al. Dental infection of Porphyromonas gingivalis induces preterm birth in mice. PLoS One. 2015;10(8):e137249. https://doi.org/10.1371/journal.pone.0137249 PMid:26322971

21. Santa Cl, Herrera D, Martin C, Herrero A, Sanz M. Association between periodontal status and pre-term and/or low-birth weight in Spain: Clinical and microbiological parameters. J Periodontal Res. 2013;48(4):443-51. https://doi.org/10.1111/jre.12024 PMid:23083427

22. Chen ZB, He L, Kang J, Huang Z, Sha YQ, Zhu WF, et al Relationship between the preterm low birth weight infant and the periodontal pathogen bacteria in maternal saliva. Beijing $\mathrm{Da}$ Xue Xue Bao. 2012;44(1):29-33.

PMid:22353895

23. Jang $\mathrm{H}$, Patoine $\mathrm{A}$, Wu TT, Castillo DA, Xiao J. Ora microflora and pregnancy: A systematic review and metaanalysis. Sci Rep. 2021;11(1):16870. https://doi.org/10.1038/ s41598-021-96495-1

PMid:34413437 